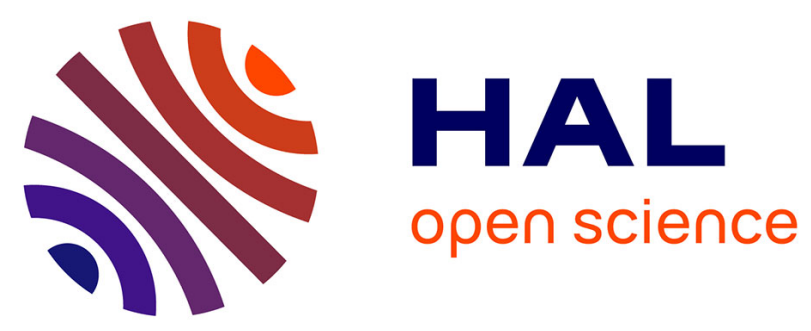

\title{
An innovative method based on grain angle measurement to sort veneer and predict mechanical properties of beech laminated veneer lumber
}

Joffrey Viguier, Christophe Bourgeay, Anti Rohumaa, Guillaume Pot, Louis

Denaud

\section{To cite this version:}

Joffrey Viguier, Christophe Bourgeay, Anti Rohumaa, Guillaume Pot, Louis Denaud. An innovative method based on grain angle measurement to sort veneer and predict mechanical properties of beech laminated veneer lumber. Construction and Building Materials, 2018, 181, pp.146-155. 10.1016/j.conbuildmat.2018.06.050 . hal-01874799

\author{
HAL Id: hal-01874799 \\ https://hal.science/hal-01874799
}

Submitted on 14 Sep 2018

HAL is a multi-disciplinary open access archive for the deposit and dissemination of scientific research documents, whether they are published or not. The documents may come from teaching and research institutions in France or abroad, or from public or private research centers.
L'archive ouverte pluridisciplinaire $\mathbf{H A L}$, est destinée au dépôt et à la diffusion de documents scientifiques de niveau recherche, publiés ou non, émanant des établissements d'enseignement et de recherche français ou étrangers, des laboratoires publics ou privés. 


\title{
An innovative method based on grain angle measurement to sort veneer and predict mechanical properties of beech laminated veneer lumber
}

Joffrey Viguier ${ }^{\mathrm{a},}$, Christophe Bourgeay ${ }^{\mathrm{a}}$, Anti Rohumaa ${ }^{\mathrm{a}}$, Guillaume Pot $^{\mathrm{a}}$, Louis Denaud ${ }^{\mathrm{a}}$

${ }^{a}$ LaBoMaP, Arts \& Métiers ParisTech, rue Porte de Paris, F-71250 Cluny, France

\begin{abstract}
This study proposes an innovative model based on local grain angle measurements to predict the modulus of elasticity of LVL made from beech. It includes a veneers sorting method industrially compatible thanks to its low computational time. For this study 41 LVL panels were prepared from 123 beech sheets of veneers. Local grain angle was obtained with a two dimensional scanner and veneer density was measured. Several models based on these measurements have been developed and their ability to predict the modulus of elasticity of LVL panels have been compared. The model based only on local grain angle measurements have been proven more efficient than models taking into account the veneer density. The proposed method can be used to sort veneer during the peeling process and grade the production of LVL panels to optimize their mechanical properties even for low-quality veneer.
\end{abstract}

Keywords: Laminated Veneer Lumber, grain angle, mechanical properties, beech, grading

Email address: joffrey.viguier@gmail.com (Joffrey Viguier) 
1 List of main symbols :

$\begin{array}{ll}\rho_{\text {veneer }} & \text { Veneer density } \\ \theta(x, y) & \text { Local grain angle } \\ E_{\text {veneer }}(x, y) & \text { Local modulus of elasticity of veneer } \\ \bar{E}_{\text {veneer }} & \text { Averaged local modulus of elasticity of veneer } \\ E_{\text {glob,exp }} & \text { Global modulus of elasticity assessed by static bending } \\ E_{\text {ply }}(x, y) & \text { Local modulus of elasticity of veneer with variables } \\ & \text { parameters } \\ E_{\text {mean }}(x) & \text { Averaged local modulus of elasticity along the width } \\ & \text { of veneer } \\ E_{\text {glob,mod }}(\rho) & \text { MOE calc. on basis of the proposed model taking into } \\ & \text { account only the density } \\ E_{\text {glob,mod }}(G A) & \text { MOE calc. on basis of the proposed model taking into } \\ \bar{\theta}_{\text {abs,veneer }} & \text { account only the grain angle } \\ \bar{E}_{\text {panel-opti }} & \text { MOE calc. on basis of the proposed model taking into } \\ \bar{E}_{\text {panels }}(\rho+G A) & \text { Average of } E_{\text {ply }}(x, y) \text { of the three constitutive plies } \\ & \text { account both the density and grain angle } \\ & \text { Average of } E_{\text {veneer }}(x, y) \text { of the three constitutive plies } \\ & \text { Avarameters }\end{array}$



5 wood products for structural purpose has increased in Europe, particularly

\section{Introduction}

in France and Germany, where these renewable resources are available and not used to their fullest extent. Laminated veneer lumber (LVL) is made from rotary peeled veneers that have been dried and then glued together.

The grain direction of the layers is mainly oriented in the same direction and parallel to its length [1]. This product has exhibited superior mechanical properties in axial bending tests compared to solid wood even when manufactured from lower-grade logs $[2,3]$. In LVL, the defects are randomly distributed throughout the cross-section, which prevents the concentration of stresses at specific locations. Moreover, using low-grade veneers in the inner plies can reduce the processing costs without significant decrease in mechanical properties. Furthermore, the aesthetic value of the final product is conserved by using free-defect veneers only for visible sides. This approach is well known for drawing full benefit from second quality wood.

The mechanical properties of LVL can be affected by several factors such as juvenile wood $[4,5]$, jointing method [6], lathe checks $[7,8]$, load direction $[9,10]$, veneer thickness [11] or sylvicultural pratice [12].

To predict the mechanical properties of LVL some non-destructive testing (NDT) methods were studied in the literature to evaluate the bending properties. A study on red maple[13] showed that the flexural properties of LVL can be predicted using ultrasonic method and suggested that the performance of LVL can potentially be enhanced through ultrasonic rating of individual veneer sheets. The same conclusions have been made in a study 
for LVL made of Schizolobium parahayba [14]. Another study conducted on southern pine [15] used ultrasonic method and transverse vibration and showed that the prediction of the bending stiffness using these methods is less accurate and reliable for LVL compared to solid wood. Pu and Tang [15] also found a significant effect of veneer grade on the modulus of elasticity (MOE) of LVL. The efficiency of ultrasonic methods for two different species has also been discussed by de Souza et al. [16] and it has been shown that the correlation with the MOE was significant for Pinus kesiya and that there was no correlation for Pinus oocarpa.

The wood material presents a very high variability arising from several factors. In particular, many studies have shown the existing correlation between density and mechanical properties $[17,18,19]$ of sawn timber.

For clear wood in general, the MOE in fibers direction can be considered to depend on density and microfibril angle (MFA) [20]. However, beech wood is a very homogeneous specie regarding the density: its coefficient of variation (CV) can vary between $4 \%$ and $6 \%$ only [21, 22]. Therefore, the level of determination of MOE variation which have a CV up to $16 \%$ [22], by density is expected to be low. The variation in specific modulus (MOE divided by the density) due to tree growth (juvenility, ring width, tree slenderness, reaction wood...) is on the contrary similar to other species and driven by MFA variations.

At the timber scale, several other studies $[23,24,3]$ report the same tendencies regarding the variation of density (CV from $5 \%$ to $6 \%$ ). More than 1800 timber beams of beech were characterized in [23], the coefficient variation of MOE was found to be up to $20 \%$ (mean value equal to 14100 
$\mathrm{MPa}$ ) for a coefficient variation of density equal to $6 \%$ (mean value equal to $\left.670 \mathrm{~kg} \cdot \mathrm{m}^{-3}\right)$. Another study on compression and tension properties of beech lamination [24] stated that due to its low variation (CV of 5\%), density could not contribute significantly to the strength and stiffness prediction. This study also showed the poor correlation existing between density and modulus of elasticity in both tension and compression tests, with a coefficient of determination found between the density and the modulus of elasticity lower than 0.06 .

For beech LVL, the variation of density according to [3] is also low (CV lower than 5\%). In addition, the authors didn't even tried to grade the veneers according to density based on previous study [25] stating that there were no relationship between density and strength properties for beech wood.

Moreover, local singularities such as knots and grain angle have a strong influence on the mechanical properties. Indeed, the authors of [24] finally concluded that strength and stiffness are mainly determined by the knot area ratio. Several studies have focused on the measurement of the local grain angle on timber $[26,27,28]$. The potential of the grain angle measurements has also been studied for strength grading of timber and it has already proven to be efficient to predict mechanical properties [29, 30, 31, 32]. Other studies $[33,34]$ have also shown the potential of grain angle measurements to predict mechanical properties of glulam beam made of spruce. To the best knowledge of the authors there are no investigations carried out on local grain angle measurement to predict LVL mechanical properties.

The main purpose of the present study is to develop a method based on grain angle measurement to predict the modulus of elasticity of LVL made 
of beech. The second goal is to assess the efficiency of local grain angle measurements to grade beech LVL.

\section{Materials and methods}

\subsection{Veneers production}

Two green logs of beech from two different trees (Fagus Sylvatica L.) were selected from the plantation site of Cluny (Burgundy, France) for their high knotiness. They were soaked at $60^{\circ} \mathrm{C}$ for 24 hours and then rotary peeled using a light packaging scale lathe (SEM S500 - knife length $900 \mathrm{~mm}$ ) equipped with an angular pressure bar. The veneer's thickness was set to 2 $\mathrm{mm}$ and the compression rate was $5 \%$ of veneer thickness (a gap of $1.9 \mathrm{~mm}$ between cutting face and pressure bar nose). Subsequently the veneers were dried in a vacuum dryer with heating plates to limit waviness and to reach about $12 \%$ moisture content. Afterward, dried veneers were cut to $600 \times$ $75 \mathrm{~mm}^{2}$ and conditioned in a climatic chamber for $72 \mathrm{~h}$ at a temperature of $20{ }^{\circ} \mathrm{C}$ and $65 \%$ of relative humidity. After conditioning, each veneer was weighed to obtain their average specific density $\rho_{\text {veneer }}$. In total, 123 veneers were prepared for this study.

\subsection{Grain angle measurement}

Each veneer sheet was characterized with an optical scanner designed to measure the local grain angle (BobiScan, LaBoMaP). The grain angle is measured by projecting a line of laser spots on the surface of the veneer. As a result of wood anisotropic light diffusion properties, an elliptic pattern oriented parallel to the projection of the fibers axis can be observed on veneer 
surface. The grain angle can be obtained with Principal Component Analysis applied on each ellipse binarized image. The grain angle evolution over the whole veneer surface is obtained by illuminating the surface with several laser spots along a line (Figure 1 a). The grain angle measurement has been conducted only on one face of each veneer (it has been considered that the grain angle is the same through the section since the thickness is only 2 $\mathrm{mm}$ ). An example of the grain angle measurement is shown in Figure 1 (b) where the resolution is $1 \mathrm{~mm}$ in $\mathrm{x}$ direction and $5 \mathrm{~mm}$ in $\mathrm{y}$ direction. As a final step, a linear interpolation of the raw data was conducted to obtain a regular grid (Figure $1(\mathrm{c})$ ). This accurate technique allows to observe the strong deviations of the fibre direction around knots.

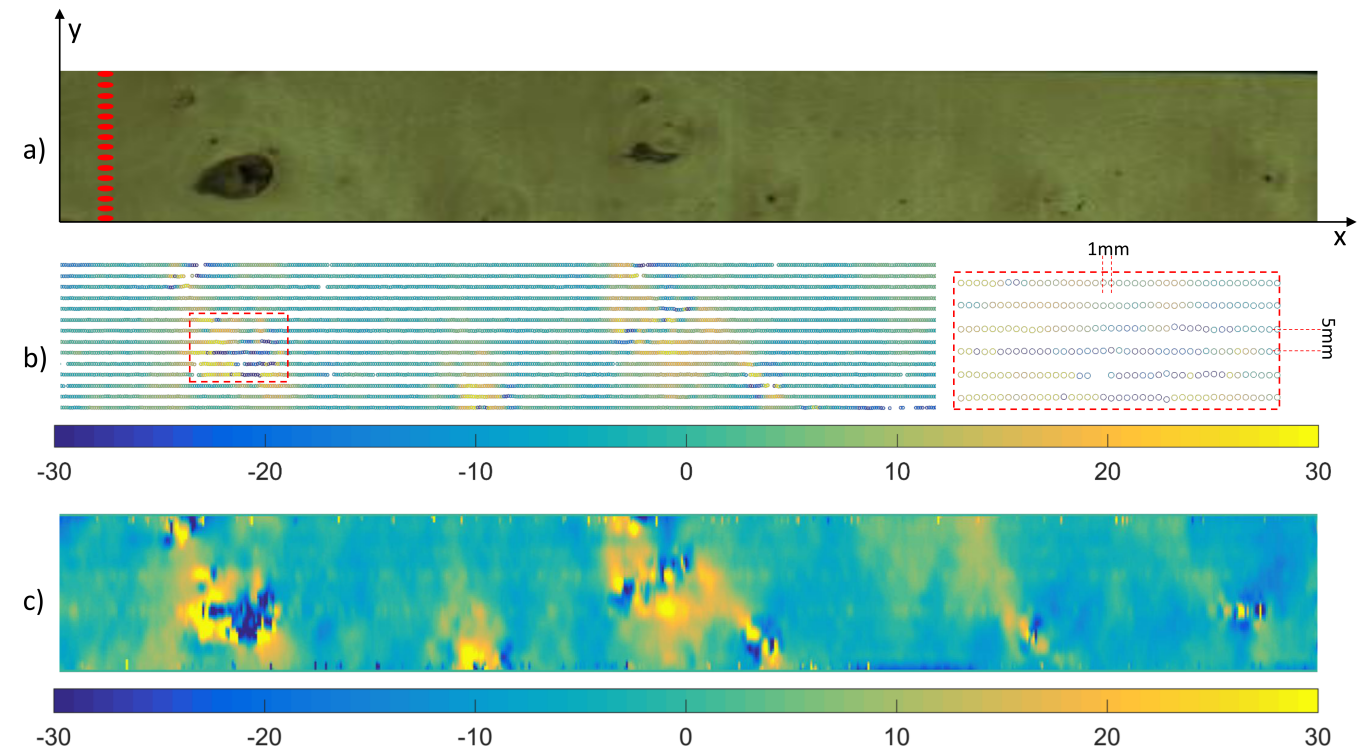

Figure 1: Local grain angle measurement: a) photography, b) raw data c) interpolated data $\theta(x, y)\left(\right.$ Angles are represented in $\left.{ }^{\circ}\right)$ 


\subsection{LVL panel manufacturing}

The 41 three plies LVL panels were prepared with dimensions $6 \times 75 \times$ $600 \mathrm{~mm}^{3}$ out of 123 veneer sheets. A commercial Polyvinyl acetate (PVAc) formulation (0892 100, Wurth) with a spread rate of approximately $150 \mathrm{~g} / \mathrm{m}^{2}$ was used. The panels were pressed in a hydraulic press at 3 bars. To maximize the panels mechanical properties variability, the veneers were sorted according to the grain angle measurement $\theta(x, y)\left(^{\circ}\right)$ and their density $\rho_{\text {veneer }}$ $\left(\mathrm{kg} / \mathrm{m}^{3}\right)$; this variability maximization is described below.

For each veneer, a local modulus of elasticity $E_{\text {veneer }}(x, y)(\mathrm{MPa})$ was calculated using Equation 1.

$$
E_{\text {veneer }}(x, y)=\left(E_{0}\left(\frac{\rho_{\text {veneer }}}{1000}\right)^{n_{\rho}}\right) \frac{k}{\sin ^{n}(\theta(x, y))+k \cos ^{n}(\theta(x, y))}
$$

This equation is based on the relationships exhibited in [35] for the modulus regarding the density $\left(E_{0}=16500 \mathrm{MPa}\right.$ and $n_{\rho}=0.7$ for hardwood). The modulus on a given density is multiplied by the Hankinson formula [35]. The $k$ parameter represents the ratio between the modulus of elasticity perpendicular to the grain and the modulus of elasticity parallel to the grain and has been taken equal to $\frac{1}{15}$ according to EN 338 [36] and $n$ has been taken equal to 2 .

Finally, an average modulus of elasticity $\left(\bar{E}_{\text {veneer }}\right)$ was computed for each veneer using Equation 2.

$$
\bar{E}_{\text {veneer }}=\frac{\sum_{x=1}^{n_{x}} \sum_{y=1}^{n_{y}} E_{\text {veneer }}(x, y)}{n_{x} n_{y}}
$$

The variables $n_{x}$ and $n_{y}$ respectively represent the number of pixels in $\mathrm{x}$ and y direction. Subsequently, veneers were grouped by 3 in ascending order 


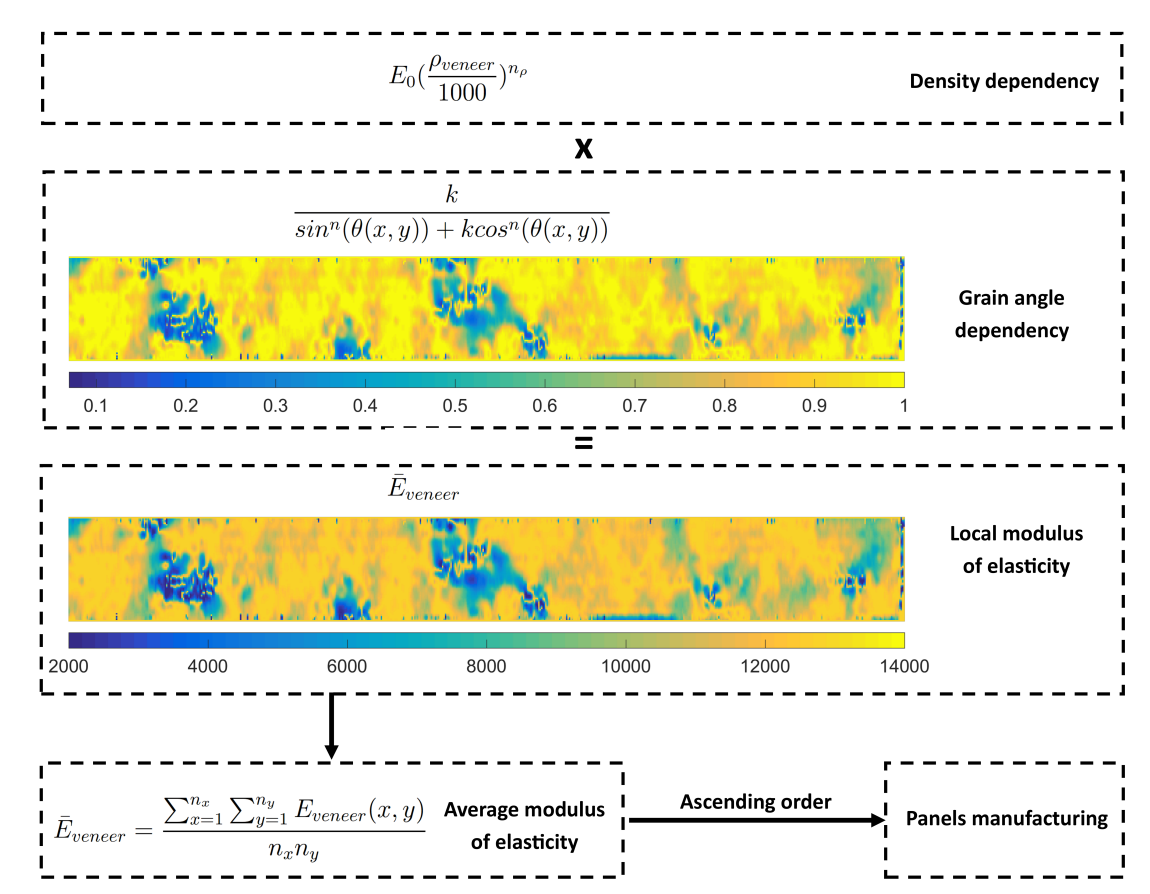

Figure 2: Overview of veneers sorting and panels manufacturing process

according to $\bar{E}_{\text {veneer }}$ to form the three-ply panels. This process is presented in Figure 2.

\subsection{Mechanical testing}

Prior to mechanical testing, all panels were conditioned in a climatic chamber for $72 \mathrm{~h}$ at a temperature of $20{ }^{\circ} \mathrm{C}$ and $65 \%$ relative humidity. The panels were tested in four-points bending test as shown in Figure 3. The global modulus of elasticity was calculated according to Equation 3, where $h$ and $b$ are respectively the beam thickness and depth, $a$ is equal to $143 \mathrm{~mm}$, $l$ is the span, F2 - F1 is an increment of load (N) on the linear regression 
142 (on the load vs. displacement curve), and w2 - w1 is the increment of global displacement (mm) corresponding to the load increment F2 - F1.

$$
E_{\text {glob,exp }}=\frac{3 a l^{2}-4 a^{3}}{4 b h^{3} \frac{w_{2}-w_{1}}{F_{2}-F_{1}}}
$$

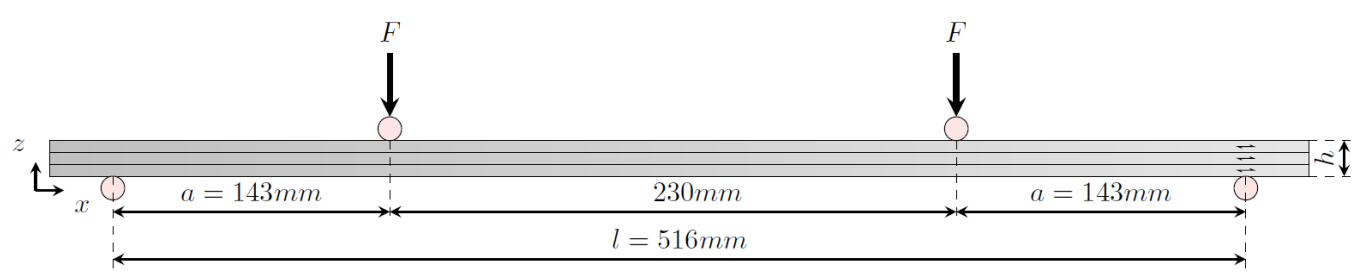

Figure 3: LVL mechanical test setup in 4 points-bending

\subsection{Analytical models: prediction of the LVL mechanical properties}

In this section, three models based on veneer density, local grain angle measurements or a combination of both are presented and their ability to predict the modulus of elasticity of LVL panels are compared.

\subsubsection{Estimation of the global modulus of elasticity}

The first step is to assign a modulus of elasticity $E_{p l y}(x, y)$ to each veneer constituting a ply of the LVL panel. The difference between the three models rely on the calculation of $E_{p l y}(x, y)$. For the model based only on the veneer density, $E_{p l y}(x, y)$ is calculated using Equation 4. Equation 5 and 6 are used for the models using only local grain measurements and a combination of both density and grain angle respectively.

$$
E_{\text {ply }}(x, y)=E_{0} \times\left(\frac{\rho_{\text {veneer }}}{1000}\right)^{n_{\rho}}: \text { Density }
$$




$$
\begin{gathered}
E_{p l y}(x, y)=E_{0} \times \frac{k}{\sin ^{n}(\theta(x, y))+k \times \cos ^{n}(\theta(x, y))}: \text { Grainangle } \\
E_{p l y}(x, y)=\left(E_{0} \times\left(\frac{\rho_{\text {veneer }}}{1000}\right)^{n_{\rho}}\right) \times \frac{k}{\sin ^{n}(\theta(x, y))+k \times \cos ^{n}(\theta(x, y))}: \text { Grain angle \& Density }
\end{gathered}
$$

The parameter $E_{0}$ is a constant representing the modulus of elasticity parallel to the grain, $n_{\rho}$ a constant, $k$ the ratio between $E_{0}$ and $E_{90}$ and $n$ a constant. The parameters in these equation are the same as in Equation 1, but in this part their values are changing (see Table 1).

In the second step $E_{p l y}(x, y)$ was averaged along the y-direction to obtain a profile $E_{\text {mean }}(x)$ of the modulus of elasticity along the x-direction for each LVL ply. Using these profiles, an effective bending stiffness $(E I)_{\text {eff }}$ was calculated for each section along the x-direction of the LVL panels, according to the Equation 7.

$$
(E I)_{e f f}(x)=\sum_{p l y=1}^{n_{p l y}=3}\left(E_{\text {mean }, p l y}(x) I_{\text {ply }}+E_{\text {mean }, p l y}(x) A_{\text {ply }} d_{p l y}(x)^{2}\right)
$$

Where $A_{p l y}, I_{p l y}$ and $d_{p l y}(x)$ are respectively: the area, the second moment of area, and the distance from the neutral fibre of each element at a given $\mathrm{x}$ position. $n_{p l y}$ is the total number of plies in $\mathrm{z}$ direction.

In this section, the deflection at mid-span in the case of a four point bending test $\left(v\left(\frac{l}{2}\right)\right)$ of the modeled panels is calculated to obtain $E_{\text {glob,mod }}$ which can be assimilated to an equivalent of $E_{\text {glob,exp }}$. The deflection at 
mid-span $\left(v\left(\frac{l}{2}\right)\right)$ of the modeled panels can be calculated using the MüllerBreslau's principle (see Equation 8).

$$
v\left(\frac{l}{2}\right)=\sum_{i=1}^{n_{x}} \frac{M_{f, i} M_{v, i}}{(E I)_{e f f, i}} \Delta x
$$

$M_{f}$ is the bending moment during a 4-points bending test, $M_{v}$ is the bending moment induced by an unitary load at midspan, $(E I)_{\text {eff }}$ is the effective bending stiffness calculated previously which is dependent of the local modulus of elasticity, $n_{x}$ is the number of elements along x direction, and $\Delta x=1 \mathrm{~mm}$ corresponds to the resolution of the images along $\mathrm{x}$ direction.

The modulus of elasticity was calculated according to the beam theory in 4 point bending using Equation 9.

$$
E_{g l o b, \text { mod }}=\frac{3 a l^{2}-4 a^{3}}{4 b h^{3} \frac{v\left(\frac{l}{2}\right)}{F}}
$$

$\mathrm{F}$ is the load which induced the previous bending momentum $M_{f}, \mathrm{l}$ is the span, and the mid-span deflection term $v\left(\frac{l}{2}\right)$ is the one calculated by Equation 8. $a, b$ and $h$ are the same than in Equation 3. The different steps described above, where only the grain angle is considered, are resumed in Figure 4 . 


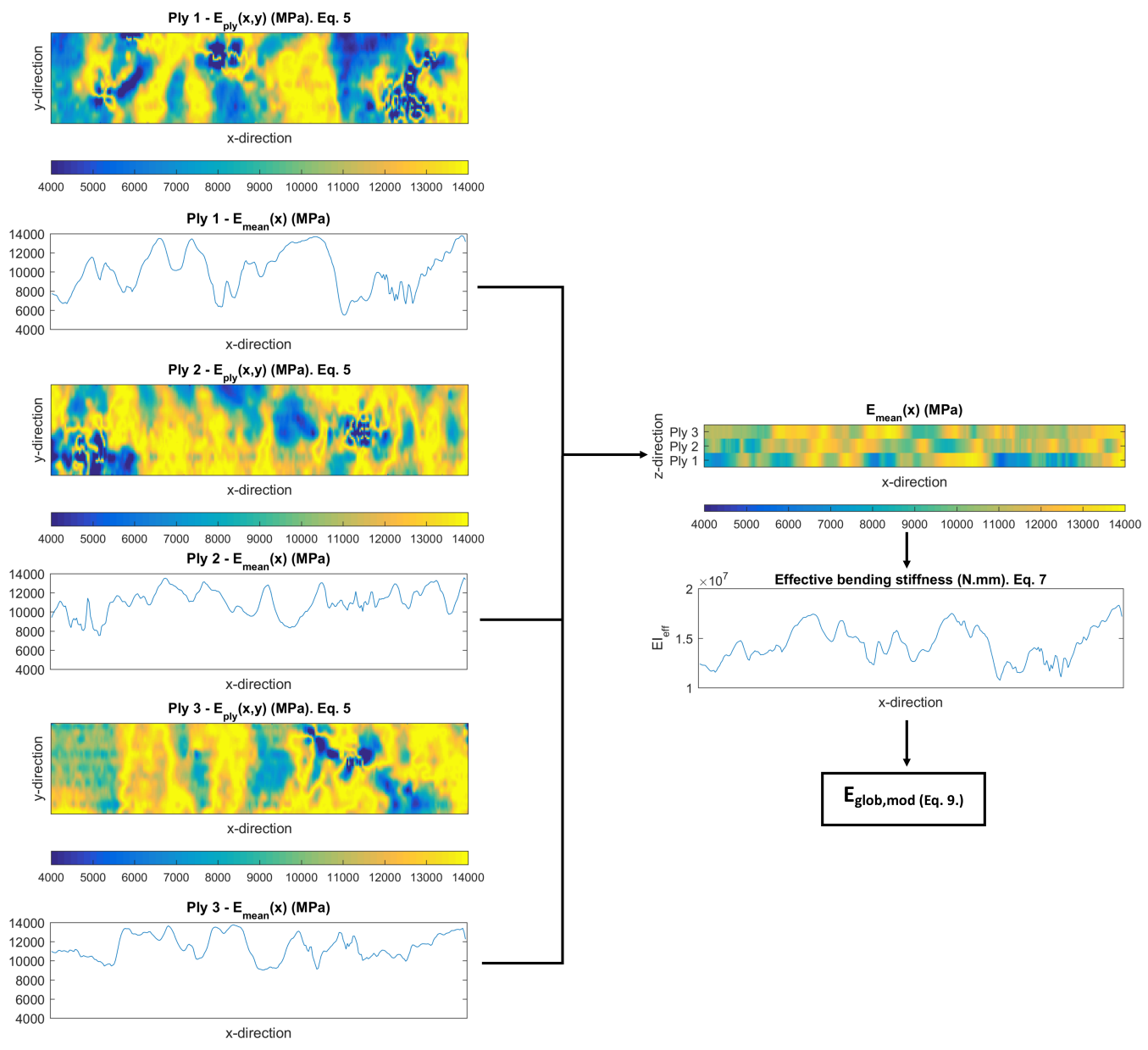

Figure 4: Principle of the analytical modeling in the case Equation 5 is used for $E_{p l y}(x, y)$ calculation 


\subsubsection{Analytical models parameters optimization}

The final predicted global modulus of elasticity depends on different parameters: $E_{0}, n_{\rho}, k$ and $n$. Different values for theses parameters can be found in the literature. In this study the relevant parameters were computed by minimizing the root mean square error (RMSE) between $E_{\text {glob,mod }}$ and $E_{\text {glob,exp }}$. Each possible $E_{\text {glob,mod }}$ has been calculated using every possible set of parameters described in Table 1. $E_{\text {glob,mod }}(\rho)$ is calculated using Equation 4, $E_{\text {glob,mod }}(G A)$ using Equation 5 and $E_{\text {glob,mod }}(\rho+G A)$ with Equation 6.

\begin{tabular}{|c|c|c|c|c|c|c|c|c|c|c|c|c|}
\hline \multirow[b]{2}{*}{ Parameters } & \multicolumn{4}{|c|}{$E_{\text {glob }, \text { mod }}(\rho)$} & \multicolumn{4}{|c|}{$E_{\text {glob,mod }}(G A)$} & \multicolumn{4}{|c|}{$E_{g l o b, \bmod }(\rho+G A)$} \\
\hline & Min & Step & Max & $\mathrm{N}$ & Min & Step & Max & $\mathrm{N}$ & Min & Step & Max & $\mathrm{N}$ \\
\hline$E_{0}$ & 8000 & 500 & 22000 & 29 & 8000 & 500 & 22000 & 29 & 8000 & 500 & 22000 & 29 \\
\hline$n_{\rho}$ & 0.1 & 0.1 & 2 & 20 & - & - & - & - & 0.1 & 0.1 & 2 & 20 \\
\hline$k$ & - & - & - & - & 0.01 & 0.005 & 0.07 & 13 & 0.01 & 0.005 & 0.07 & 13 \\
\hline \multirow[t]{2}{*}{$n$} & - & - & - & - & 1.5 & 0.05 & 2.5 & 21 & 1.5 & 0.05 & 2.5 & 21 \\
\hline & & Dete & arios & 580 & & l scen & & 7917 & & l scen & rios & 158340 \\
\hline
\end{tabular}

Table 1: Bounds, step size and number of scenario tested for each parameter of each model

\section{Results and discussions}

\subsection{Veneers physical properties}

Descriptive statistics of measured and calculated properties of the different veneers are presented in Table 2. The coefficient of variation of the veneer density $\rho_{\text {veneer }}$ is equal to $5.3 \%$ which is really close to what can be found in the literature. The average local modulus of elasticity $\bar{E}_{\text {veneer }}$ (calculated using Equation 2 i.e with parameters from the literature) seems to have a very low coefficient of variation (7.6\%) in comparison with what could be expected 
from the literature. This could be explained by the fact that the parameters used in the calculation of $\bar{E}_{\text {veneer }}$ have been computed for hardwood and not in particular for beech or simply by the fact that this parameter is a simple average and do no represent a modulus of elasticity. The mean absolute value of the local grain angle $\bar{\theta}_{a b s, v e n e e r}$ have been computed, its range goes from $1.9^{\circ}$ to $11.9^{\circ}$. In addition, the coefficient of correlation R between $\bar{\theta}_{\text {abs,veneer }}$ and $\bar{E}_{\text {veneer }}$ is equal to -0.88 showing the negative influence of the grain angle on $\bar{E}_{\text {veneer }}$. Finally, the thickness $h$ of individual veneer is also described, the mean is really close to the target and the coefficient of variation is very low $(\mathrm{CV}=3.3 \%)$.

\begin{tabular}{cccccc|ccc} 
& Min & Mean & Max & StD & $\mathrm{CV}(\%)$ & $\mathrm{R}^{2}(p$-value $)$ & $\bar{E}_{\text {veneer }}$ & $\bar{\theta}_{\text {abs,veneer }}$ \\
\hline$\rho_{\text {veneer }}$ & 588.9 & 670.9 & 761.5 & 35.6 & 5.3 & $\rho_{\text {veneer }}$ & $0.08(1.6 \mathrm{E}-3)$ & $0.04(2.1 \mathrm{E}-2)$ \\
$\bar{E}_{\text {veneer }}$ & 7958.8 & 10657.5 & 12467.6 & 813.3 & 7.6 & $\bar{E}_{\text {veneer }}$ & - & $0.77(5.5 \mathrm{E}-40)$ \\
$\bar{\theta}_{\text {abs,veneer }}$ & 1.9 & 6.0 & 11.9 & - & - & & & \\
$h$ & 1.85 & 2.02 & 2.30 & 0.07 & 3.34 & & &
\end{tabular}

Table 2: Minimum, mean, maximum, standard deviations (StD), coefficient of variation $(\mathrm{CV})$, and coefficient of determination for different measured veneer properties

\subsection{Panels physical properties}

The measured and calculated properties of the different panels, i.e density, $\bar{E}_{\text {panel }}$ (which is the average between the three $\bar{E}_{\text {veneer }}$ constitutive of each panels) and $E_{\text {glob,exp }}$ are presented in Table 3 . The mean modulus of elasticity $E_{\text {glob,exp }}$ appears quite low (9 $350 \mathrm{MPa}$ ) for LVL made of beech; indeed in the literature [3], this value reach approximately $16000 \mathrm{MPa}$. This might be due to two reasons, the first one is that only very low quality veneers have been used and the second one is that the panels are only composed of 
three veneers which reduce the potential for a good homogenization of the mechanical properties. The coefficient of variation of $E_{g l o b, e x p}$ is higher than in the literature [3] due to the process we used to produce the panels by maximizing the variability. The average density $\rho_{\text {panels }}$ (which is the average between the three $\rho_{\text {veneer }}$ constitutive of each panels) is on the contrary close to what can be found in the literature. The coefficient of determination between $\rho_{\text {panels }}$ and $E_{\text {glob,exp }}$ is only equal to 0.12 and this correlation is not significant at the 0.01 level $(p$-value $=0.026)$. Furthermore, the coefficient of variation of $\rho_{\text {panels }}$ is only $3.9 \%$ maybe due to the fact that only two logs have been used and probably leads to a density explaining only $12 \%$ of $E_{\text {glob,exp }}$ variance. A relatively good correlation exists between $\bar{E}_{\text {panel }}$ and $E_{\text {glob,exp }}$ $\left(R^{2}=0.69, p\right.$-value $\left.=9.4 \mathrm{E}-12\right)$ which corroborate the efficiency of the grain angle measurement to predict mechanical properties of LVL made of beech. Nevertheless, the range and the coefficient of variation of $\bar{E}_{\text {panel }}$ is much lower than the ones for $E_{\text {glob,exp }}$. This result highlights the fact that a true computation of a modeled modulus is needed instead of a simple average and also that some optimization is needed on the parameters involved in $\bar{E}_{\text {panel }}$ calculation.

\begin{tabular}{cccccc|ccc} 
& Min & Mean & Max & StD & CV $(\%)$ & $\mathrm{R}^{2}($ p-value $)$ & $\rho_{\text {panels }}$ & $\bar{E}_{\text {panel }}$ \\
\hline$E_{\text {glob,exp }}$ & 5504.1 & 9348.8 & 14442.6 & 1985.9 & 21.2 & $E_{\text {glob,exp }}$ & $0.12(0.026)$ & $0.69(9.4 \mathrm{E}-12)$ \\
$\rho_{\text {panels }}$ & 624.3 & 670.9 & 748.9 & 26.6 & 3.9 & $\rho_{\text {panels }}$ & - & $0.29(2.5 \mathrm{E}-4)$ \\
$\bar{E}_{\text {panel }}$ & 8541.6 & 10657.5 & 12256.1 & 800.8 & 7.5 & &
\end{tabular}

Table 3: Minimum, mean, maximum, standard deviations (StD), coefficient of variation $(\mathrm{CV})$, and coefficient of determination for different measured panel properties

Furthermore, one can notice that the coefficient of variation of $\bar{E}_{\text {panel }}$ and 
$\bar{E}_{\text {veneer }}$ are really close to each other $(7.5 \%$ and $7.6 \%$ respectively). This result could be surprising since one of the advantage of producing LVL is to homogenize the mechanical properties. However, it was expected in this study because of the process used to select the constitutive veneer of each panels in ascending order of $\bar{E}_{\text {veneer }}$ to maximize their variability. The average coefficient of variation of $\bar{E}_{\text {panel }}$ that could have been observed if the veneers had been selected at random is approximately $4.4 \%$. This value have been calculated thanks to randoms permutation of $\bar{E}_{\text {veneer }}$ to constitute LVL panels and is the average coefficient of variation observed for 1000 repetitions.

\subsection{Prediction of the LVL properties by analytic modeling}

\subsubsection{Model based only on density $E_{\text {glob,mod }}(\rho)$}

The results of the model using only the density as input data are presented in Figure 5. The left part of the Figure 5 shows the sensibility analysis of the two parameters involved in this model $\left(n_{\rho}\right.$ and $\left.E_{0}\right)$. The z-axis and the colors represents the RMSE between $E_{\text {glob,mod }}(\rho)$ and $E_{\text {glob,exp. }}$. It can be seen that a significant amount of parameters can give nearly the same results (i.e a RMSE value close to $2000 \mathrm{MPa}$ ) revealing the poor correlation between density and modulus of elasticity. The optimal parameters are 1.9 and 20000 respectively for $n_{\rho}$ and $E_{0}$. The corresponding RMSE for this scenario is equal to $1841.3 \mathrm{MPa}$, the coefficient of determination is equal to 0.12 and has nearly the same level of significance than the one between $\rho_{\text {panels }}$ and $E_{\text {glob,exp }}(p$-value $=0.027)$. Those results show that taking into account the position of the different plies and the bending solicitation does not improve the prediction of the final modulus of elasticity if only the density is considered as an input data. 


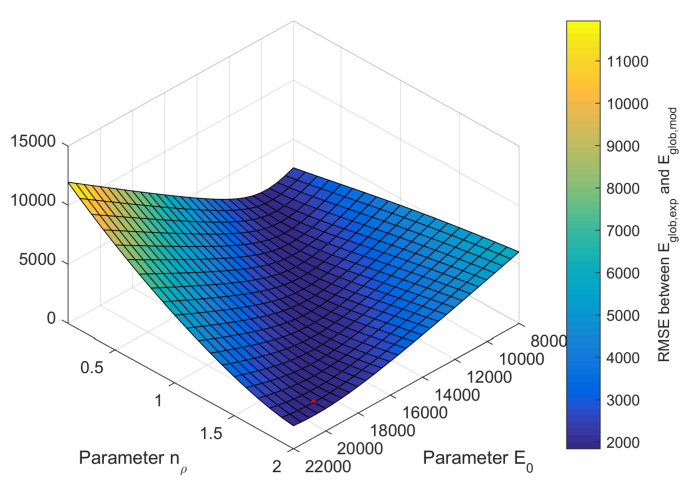

a)

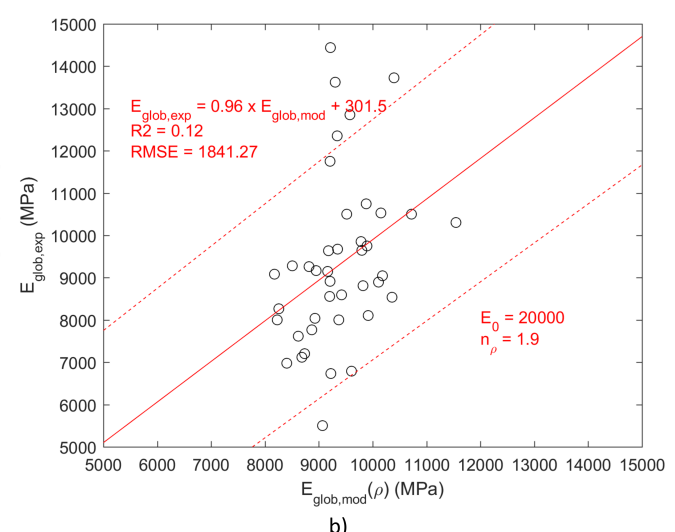

Figure 5: a) Sensibility analysis of the different parameters and b) prediction results for $E_{\text {glob,mod }}(\rho)$

\subsubsection{Model based only on grain angle $E_{\text {glob, mod }}(G A)$}

The results of the different simulations for the model taking into account only the grain angle measurement are presented in Figure 6 . The Figure 6 (a) represents the RMSE between $E_{\text {glob,exp }}$ and $E_{\text {glob,mod }}(G A)$ on the basis of $E_{0}$ parameter. Each vertical set of points (at a given $E_{0}$ ) represents the total amount of simulation in which the $k$ and $n$ parameters vary. The smallest RMSE is found for $E_{0}=16000 \mathrm{MPa}$ and the variation between $E_{0}=14000$ and $E_{0}=18000 \mathrm{MPa}$ is quite low. The largest part of the variation of the RMSE is due to the variation of the two other parameters ( $k$ and $n$ ). The sensibility analysis of those parameters for the optimal $E_{0}$ is presented in Figure 6 (b). The minimum of the RMSE is reached for $k$ $=0.02$ and $n=1.75$, it can be noted than other sets of these parameters give similar results. The Figure 6 (c) shows the comparison in terms of MOE variation according to grain angle for the optimal parameters compared to 
parameters declared by two commercial LVL producers (beech LVL from Pollmeier and Kerto-S tested in flatwise from Mets Wood). The ratio $k$ is equal to $\frac{470}{16800}=0.028$ for beech LVL and $\frac{130}{1380}=0.009$ for Kerto-S. The $n$ parameter is taken equal to 2 in accordance with EN 1995. The influence of the grain angle seems to be much larger according to this comparison at least in the case of beech LVL produced by Pollmeier. This could be due to the fact that the grain angle deviation in the present study is mainly caused by the presence of knots. Thereby, in the vicinity of knots, diving angle is probably also present which induce an even higher reduction of the mechanical properties. Also, the contribution of the shear modulus is not taken into account in this formula and could lead to a virtual decrease of the $n$ parameter. Those facts could explain why an higher influence of the grain angle is found by the optimization process. The optimal parameters are anyways consistent within the comparison given in Figure 6 (c). Finally, the quality of the prediction using optimal parameters is presented in Figure 6 (d). The coefficient of determination is equal to 0.73 , and the RMSE is equal to $1028.82 \mathrm{MPa}$ which indicates the efficiency of grain angle measurements in order to predict mechanical properties of LVL. 

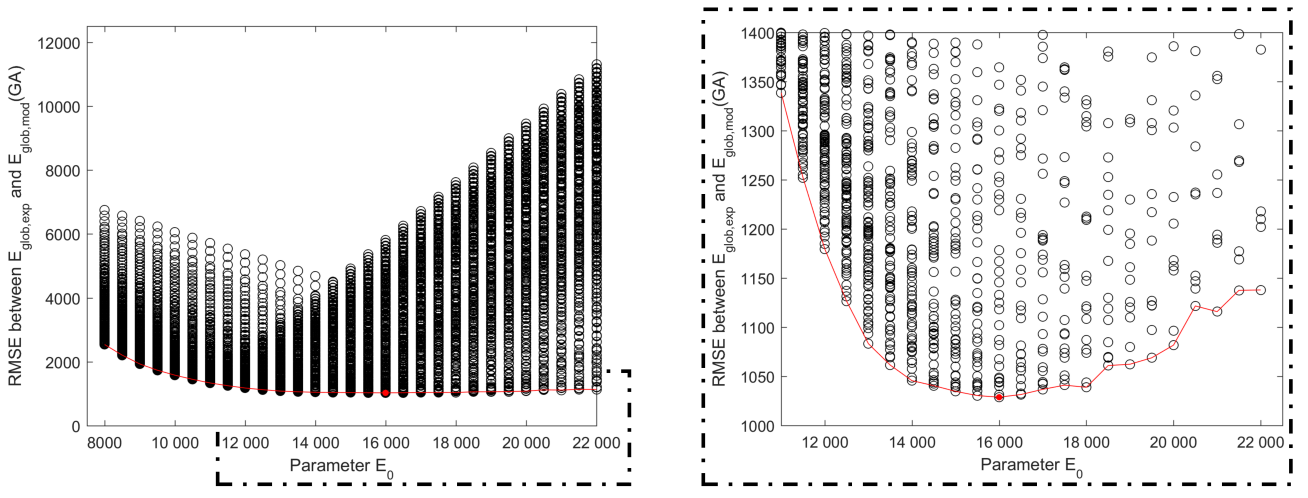

a)
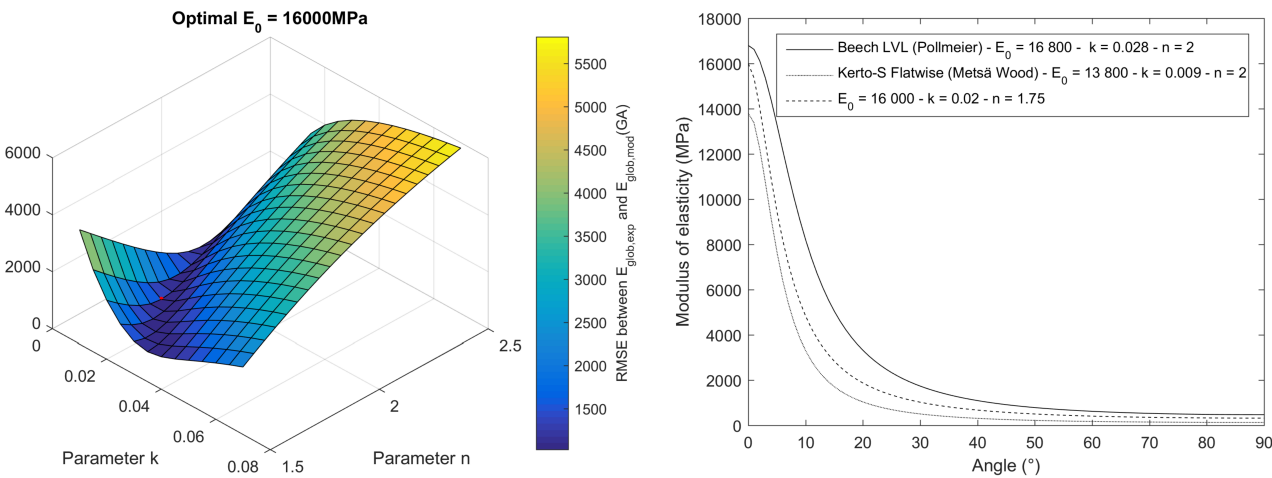

b)

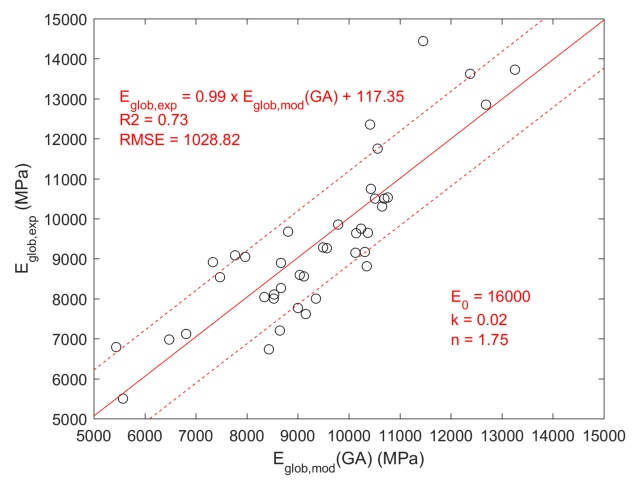

d)

Figure 6: a) Sensibility analysis for $E_{0}$ parameter, b) sensibility analysys for $k$ and $n$ parameters, c) relevance of the different parameters and d) prediction results for $E_{\text {glob,mod }}(G A)$ 


\subsubsection{Model based on density and grain angle $E_{\text {glob,mod }}(\rho+G A)$}

The results of the developed model taking into account both the density and the grain angle is given in Figure 7. The coefficient of determination between $E_{\text {glob,exp }}$ and $E_{\text {glob,mod }}(\rho+G A)$ is equal to 0.72 and the RMSE to $1148 \mathrm{MPa}$. Those results are actually lower than in the case of $E_{\text {glob,mod }}(G A)$. Since the result depends on four parameters it is difficult to plot the influence of the different parameters. The optimization sets the $n_{\rho}$ parameter close to 0 when the grain angle is part of the input data, which indicates the low influence of the density. The part of the equation modeling this dependency only represents a variation of less than $300 \mathrm{MPa}$ for the studied batch of panels when $n_{\rho}=0.1$.

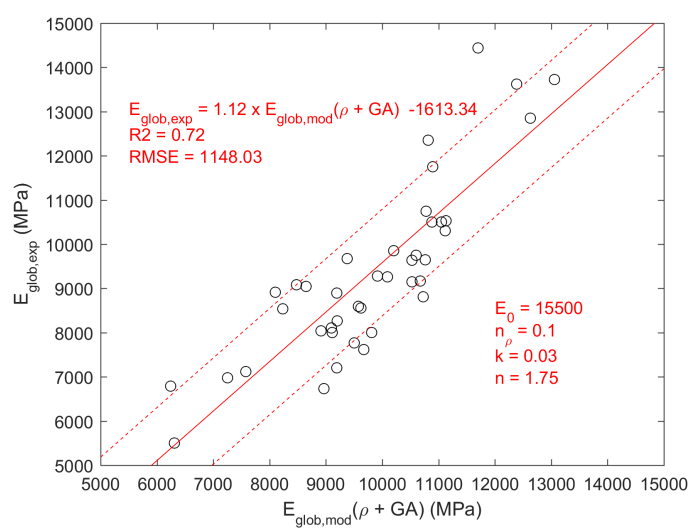

Figure 7: Prediction results for $E_{\text {glob,mod }}(\rho+G A)$

\subsubsection{Potential of different methods to predict the modulus of elasticity}

A summary of the correlation obtained between different measured or calculated estimates and $E_{\text {glob,exp }}$ is presented in Table 4 . The analysis of results reveals that the density is not a suitable predictor of the modulus of 
elasticity of LVL made of beech. Indeed, the coefficients of determination between $E_{\text {glob,exp }}$ and respectively $\rho_{\text {panels }}$ and $E_{\text {glob,mod }}(\rho)$ are both equal to 0.12. Even after taking into account the density differences in each ply and modeling a 4-points bending test, the correlation is still rather low with a low significance level. On the contrary, the coefficient of determination between $E_{\text {glob,mod }}(G A)$ and $E_{\text {glob,exp }}$ is equal to 0.73 , which is even better than the coefficient of determination between $E_{\text {glob,mod }}(\rho+G A)$ and $E_{\text {glob,exp }}$. Taking both the density and the grain angle into account has not been proven to be useful due to the low correlation existing between density and the global modulus of elasticity.

The coefficient of determination between $\bar{E}_{\text {panel }}$ and $\bar{E}_{\text {panel-opti }}$ (which is calculated in the same way as $\bar{E}_{\text {panel }}$ but with the optimal parameters found for $\left.E_{\text {glob,mod }}(G A)\right)$ and $E_{\text {glob,exp }}$ are respectively equal to 0.69 and 0.71 . This is slightly lower than the one between $E_{\text {glob,mod }}(G A)$ and $E_{\text {glob,exp }}$ but this rather high correlation is an encouraging result to sort veneers in order to produce LVL made of beech. Indeed, these properties do not take into account the layup or the type of loading and could easily be used in a production line to grade and sort veneers. However, these results are based on 3-ply panels, and the difference between the mechanical models and the simple averaging might be higher in the case of LVL panels with a higher number of plies. Indeed, in this case the plies in the outer part have a much higher influence that the ones in the inner part, which can only be taken into account with a model such as the one described here.

The range of the obtained values and their coefficient of variation are also described in Table 4 . The closest range compared to $E_{\text {glob,exp }}$ is found 
for $E_{\text {glob,mod }}(G A)$. The difference of optimizing the different parameters on the coefficient of variation can also be seen : the coefficient of variation goes from $7.5 \%$ to $12.6 \%$ for $\bar{E}_{\text {panel }}$ and $\bar{E}_{\text {panel-opti }}$ respectively. An improvement in terms of coefficient of variation thanks to the modeling is also observable : the coefficient of variation goes from $12.6 \%$ for $\bar{E}_{\text {panel-opti }}$ to $18.3 \%$ for $E_{\text {glob,mod }}(G A)$. This coefficient of variation is really close to the one observed for $E_{g l o b, e x p}(21.2 \%)$.

\begin{tabular}{|c|c|c|c|c|c|c|c|c|c|c|c|}
\hline & \multicolumn{5}{|c|}{ Statistics } & \multicolumn{2}{|c|}{ Correlation } & \multicolumn{4}{|c|}{ Parameters } \\
\hline & Min & Mean & Max & Std & CV (\%) & $\mathrm{R} 2$ & $p$-value & $E_{0}$ & $n_{\rho}$ & $k$ & $n$ \\
\hline$\rho_{\text {panels }}$ & 624.3 & 670.9 & 748.9 & 26.6 & 3.9 & 0.12 & 0.026 & - & - & - & - \\
\hline $\bar{E}_{\text {panel }}$ & 8541.6 & 10657.5 & 12256.1 & 800.8 & 7.5 & 0.69 & $9.4 \mathrm{E}-12$ & 16500 & 0.7 & 0.07 & 2 \\
\hline$E_{\text {glob,mod }}(\rho)$ & 8171.1 & 9381.3 & 11545.3 & 711.3 & 7.6 & 0.12 & 0.027 & 20000 & 1.9 & - & - \\
\hline$E_{\text {glob,mod }}(G A)$ & 5441.6 & 9350.6 & 13252.8 & 1712.8 & 18.3 & 0.73 & $1.7 \mathrm{E}-12$ & 16000 & - & 0.02 & 1.75 \\
\hline$E_{\text {glob,mod }}(\rho+G A)$ & 6245.8 & 9818.1 & 13057.9 & 1511.9 & 15.4 & 0.72 & $2 \mathrm{E}-12$ & 15500 & 0.1 & 0.03 & 1.75 \\
\hline $\bar{E}_{\text {panel-opti }}$ & 7488.9 & 11128.1 & 13841.6 & 1398.4 & 12.6 & 0.71 & $5 \mathrm{E}-12$ & 16000 & - & 0.02 & 1.75 \\
\hline$E_{\text {globexp }}$ & 5504.1 & 9348.8 & 14442.6 & 1985.9 & 21.2 & - & - & - & - & - & - \\
\hline
\end{tabular}

Table 4: Summary of the relationship between measured or calculated properties and $E_{\text {glob,exp }}$

\subsection{Grading LVL panels according to grain angle}

In order to evaluate the potential of this method to grade LVL panels, a grading method inspired by the method used to perform strength grading of solid timber [36] is presented in Figure 8. Unlike in the case of solid timber where the characteristic bending strength and density need to fulfill requirements, in this case, only the average modulus of elasticity is considered as a required parameter to reach a grade. 
The proposed method to grade LVL is based on finding threshold values on predictive properties ( $\bar{E}_{\text {panel-opti }}$ in this case); such that panels have an average modulus of elasticity higher than a given value $(10500 \mathrm{MPa}$ in this case). To assess the efficiency of the grading, it is necessary to perform an optimal grading made on the basis of the modulus of elasticity obtained during the mechanical tests. In this case, the grading is done by sorting the values of modulus of elasticity in ascending order and removing the lowest values until the average modulus of elasticity of the remaining panels is higher than $10500 \mathrm{MPa}$. In this particular application grade 1 represents the higher grade and grade 2 the lower grade.

Knowing the optimal grading and the grading obtained by this method, it is therefore possible to assess the performance of this method. The results show remarkable accuracy of the method; the yield obtained by the method reach $51 \%$ compared to $58 \%$ obtained by the optimal grading for grade 1 .

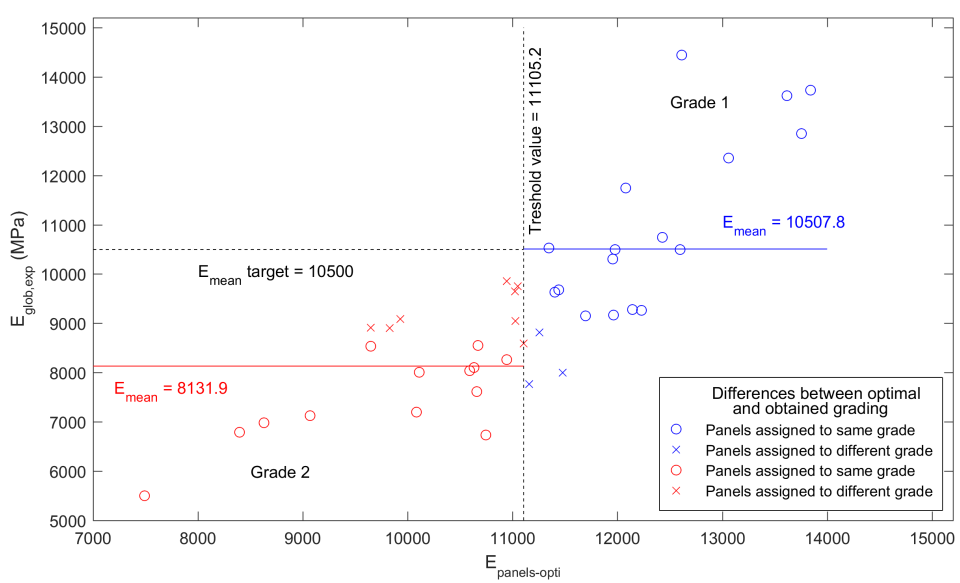

Figure 8: Method to sort panels into two grades 


\section{Conclusions}

This study shows that it is possible to predict the modulus of elasticity of LVL made of beech using local grain angle measurements. In addition, this study demonstrates that the average density is not a good predictor of the modulus of elasticity. Encouraging outcomes have been highlighted considering the sorting based on local grain angle measurements. This method can be used to efficiently define different grades of LVL panels and to lower the variability of the final product even for low grade LVL made of low quality veneer. The results presented in this study are only based on three layer panels subjected to flatwise bending. These results need to be extended to LVL composed of much more layers solicited in both loading directions. In particular, in edgewise bending the results need to be investigated. Indeed, sorting the veneer could still lead to lower the variability within grades even in edgewise but the prediction results could be less convincing. The results should also be extended with more logs. For such an extent and to improve the quality of the prediction, measuring the ultrasonic speed to take into account MFA variation which is mostly a tree effect and a property inherent to clear wood could be insightful.

\section{Acknowledgments}

The present study was financed by the company Fernand BRUGERE. This study was performed thanks to the partnership build by BOPLI: a shared public-private laboratory build between Bourgogne Franche-Compt region, LaBoMaP and the company Fernand BRUGERE. The authors would 
also like to thank the Xylomat Technical Platform from the Xylomat Scientific Network funded by ANR-10-EQPX-16 XYLOFOREST.

\section{References}

[1] CEN, EN 14374 Timber structures Structural laminated veneer lumber Requirements, 2005.

[2] I. Aydin, S. Çolak, G. Çolakoglu, E. Salih, A comparative study on some physical and mechanical properties of Laminated Veneer Lumber (LVL) produced from Beech (Fagus orientalis Lipsky) and Eucalyptus (Eucalyptus camaldulensis Dehn.) veneers, Holz als Roh- und Werkstoff 62 (3) (2004) 218-220.

[3] M. Knorz, J. van de Kuilen, Development of a high-capacity engineered wood product-LVL made of European Beech (fagus sylvatica L.), World Conference on Timber Engineering 15 (2012) 19.

[4] S. Girardon, L. Denaud, G. Pot, I. Rahayu, Modelling the effects of wood cambial age on the effective modulus of elasticity of poplar laminated veneer lumber, Annals of Forest Science 73 (3) (2016) 615-624.

[5] M. Nazerian, M. D. Ghalehno, A. B. Kashkooli, Effect of wood species, amount of juvenile wood and heat treatment on mechanical and physical properties of laminated veneer lumber, Journal of Applied Sciences 11 (6) (2011) 980-987.

[6] A. Özçifçi, Effects of scarf joints on bending strength and modulus of 
elasticity to laminated veneer lumber (LVL), Building and Environment 42 (3) (2007) 1510-1514.

[7] G. Pot, L.-E. Denaud, R. Collet, Numerical study of the influence of veneer lathe checks on the elastic mechanical properties of laminated veneer lumber (LVL) made of beech, Holzforschung 69 (3) (2015) 337345.

[8] A. Rohumaa, C. G. Hunt, M. Hughes, C. R. Frihart, J. Logren, The influence of lathe check depth and orientation on the bond quality of phenolformaldehyde-bonded birch plywood, Holzforschung 67 (7) (2013) 779786.

[9] B. C. Bal, I. Bektaş, The effects of wood species, load direction, and adhesives on bending properties of laminated veneer lumber, BioResources 7 (3) (2012) 3104-3112.

[10] M. Kiliç, The effects of the force loading direction on bending strength and modulus of elasticity in laminated veneer lumber (LVL), BioResources 6 (3) (2011) 2805-2817.

[11] R. R. de Melo, C. H. S. Del Menezzi, Influence of veneer thickness on the properties of LVL from Paricá (Schizolobium amazonicum) plantation trees, European Journal of Wood and Wood Products 72 (2) (2014) $191-198$.

[12] J. Viguier, B. Marcon, S. Girardon, L. Denaud, Effect of Forestry Management and Veneer Defects Identified by X-ray Analysis on Mechanical 
Properties of Laminated Veneer Lumber Beams Made of Beech, BioResources 12 (3) (2017) 6122-6133.

[13] X. Wang, Flexural properties of laminated veneer lumber manufactured from ultrasonically rated red maple veneer: a pilot study, US Dept. of Agriculture, Forest Service, Forest Products Laboratory, 2003.

[14] C. Del Menezzi, L. Mendes, M. De Souza, G. Bortoletto, Effect of Nondestructive Evaluation of Veneers on the Properties of Laminated Veneer Lumber (LVL) from a Tropical Species, Forests 4 (2) (2013) 270-278.

[15] J. Pu, R. Tang, Nondestructive evaluation of modulus of elasticity of southern pine LVL: Effect of veneer grade and relative humidity, Wood and fiber science 29 (3) (2007) 249-263.

[16] F. de Souza, C. Del Menezzi, G. B. Júnior, Material properties and nondestructive evaluation of laminated veneer lumber (LVL) made from Pinus oocarpa and P. kesiya, European Journal of Wood and Wood Products 69 (2) (2011) 183-192.

[17] A. Rohanovà, R. Lagana, M. Babiak, Comparison of non-destructive methods of quality estimation of the construction spruce wood grown in Slovakia, 17th international nondestructive testing and evaluation of wood symposium, Hungary, 2011.

[18] S.-Y. Wang, J.-H. Chen, M.-J. Tsai, C.-J. Lin, T.-H. Yang, Grading of softwood lumber using non-destructive techniques, Journal of materials processing technology 208 (1-3) (2008) 149-158. 
[19] A. Hanhijarvi, A. Ranta-Maunus, G. Turk, Potential of strength grading of timber with combined measurement techniques, Combigrade-project VTT Publications 568 (2008).

[20] I. Brémaud, J. Ruelle, A. Thibaut, B. Thibaut, Changes in viscoelastic vibrational properties between compression and normal wood: roles of microfibril angle and of lignin.

[21] J. Gérard, D. Guibal, S. Paradis, M. Vernay, J. Beauchêne, L. Brancheriau, I. Châlon, C. Daigremont, P. Détienne, D. Fouquet, P. Langbour, S. Lotte, M.-F. Thévenon, C. Méjean, A. Thibaut, Tropix 7 (2011).

[22] E. Pöhler, R. Klingner, T. Künniger, Beech (Fagus sylvatica L.)-Technological properties, adhesion behaviour and colour stability with and without coatings of the red heartwood, Annals of forest science 63 (2) (2006) 129-137.

[23] J.-D. Lanvin, Correspondance entre classes visuelles et classes de résistance mécanique EN 338 pour le HETRE (Fagus sylvatica) de France., Rapport comission française BF 002 LBO/JDL/403/15/170 08/04/2015, FCBA (2015).

[24] P. Glos, J. Denzler, P. Linsenmann, Strength and stiffness behaviour of beech laminations for high strength glulam, in: Proceedings Meeting, Vol. 37, Edinburgh, Scotland, 2004.

[25] P. Glos, B. Lederer, Sortierung von Buchen- und Eichenschnittholz nach der Tragfähigkeit und Bestimmung der zugehörigen Festigkeits- und 
Steifigkeitskennwerte, Tech. Rep. Bericht Nr. 98508, Institut für Holzforschung, Technische Universität München (2000).

[26] S.-P. Simonaho, J. Palviainen, Y. Tolonen, R. Silvennoinen, Determination of wood grain direction from laser light scattering pattern, Optics and Lasers in Engineering 41 (1) (2004) 95-103.

[27] J. Nyström, Automatic measurement of fiber orientation in softwoods by using the tracheid effect, Computers and electronics in agriculture 41 (1) (2003) 91-99.

[28] J. Zhou, J. Shen, Ellipse detection and phase demodulation for wood grain orientation measurement based on the tracheid effect, Optics and lasers in engineering 39 (1) (2003) 73-89.

[29] A. Olsson, J. Oscarsson, E. Serrano, B. Kallsner, M. Johansson, B. Enquist, Prediction of timber bending strength and in-member crosssectional stiffness variation on the basis of local wood fibre orientation, European Journal of Wood and Wood Products 71 (3) (2013) 319-333.

[30] J. Viguier, A. Jehl, R. Collet, L. Bleron, F. Meriaudeau, Improving strength grading of timber by grain angle measurement and mechanical modeling, Wood Material Science \& Engineering 10 (1) (2015) 145-156.

[31] A. Olsson, J. Oscarsson, Strength grading on the basis of high resolution laser scanning and dynamic excitation: a full scale investigation of performance, European Journal of Wood and Wood Products 75 (1) (2017) $17-31$. 
[32] J. Viguier, D. Bourreau, J.-F. Bocquet, G. Pot, L. Bléron, J.-D. Lanvin, Modelling mechanical properties of spruce and Douglas fir timber by means of X-ray and grain angle measurements for strength grading purpose, European Journal of Wood and Wood Products (2017) 1-15.

[33] G. Kandler, J. Füssl, E. Serrano, J. Eberhardsteiner, Effective stiffness prediction of GLT beams based on stiffness distributions of individual lamellas, Wood Science and Technology 49 (6) (2015) 1101-1121.

[34] J. Oscarsson, E. Serrano, A. Olsson, B. Enquist, Identification of weak sections in glulam beams using calculated stiffness profiles based on lamination surface scanning, in: WCTE 2014, World Conference on Timber Engineering, Quebec City, Canada, August 10-14, 2014, Université Laval, 2014.

[35] R. Bergman, Z. Cai, C. Carll, C. Clausen, M. Dietenberger, R. Falk, C. Frihart, S. Glass, C. Hunt, R. Ibach, Wood handbook: Wood as an engineering material, Forest Products Laboratory.

[36] CEN, EN 14081-4 Strength graded structural timber with rectangular cross section - Part 4: Machine grading - Grading machine settings for machine controlled systems, 2009. 